\title{
PERBANDINGAN ANALISA DAYA DUKUNG TIANG PANCANG MENGGUNAKAN METODE PERHITUNGAN L. DECOURT DAN TES PDA
}

\author{
Andyt Tegar Zakahfi $i^{1}$, Rini Kusumawardan $i^{2}$ \\ 1 Jurusan Teknik Sipil, Fakultas Teknik, Universitas Negeri Semarang (UNNES) \\ Andytcahgaruda@gmail.com \\ 2 Jurusan Teknik Sipil, Fakultas Teknik, Universitas Negeri Semarang (UNNES) \\ Rini.kusumawardani@gmail.com
}

\begin{abstract}
ABSTRAK : Dermaga IV pelabuhan Tanjung Intan Cilacap dibangun menggunakan struktur deck on pile dengan pondasi berupa tiang pancang pipa baja. Fungsi dari pondasi ini adalah untuk menyalurkan beban yang diterima oleh struktur, lalu diteruskan ke dalam tanah. Pondasi yang menopang struktur, harus memliliki daya dukung tiang yang lebih besar dari beban rencana yang diterima oleh pondasi tersebut. Pada artikel ini akan dibahas mengenai perbandingan daya dukung tiang pancang dengan analisa data lapangan dan pengujian daya dukung pondasi tiang. Metodologi pengumpulan data dilakukan dengan cara pengambilan data dari pihak proyek dan studi pustaka. Perhitungan daya dukung tiang pancang dilakukan menggunakan metode perhitungan L. Decourt (1982) dengan menggunakan data SPT yang didapatkan dari hasil pengujian tanah di area dermaga IV pelabuhan Tanjung Intan Cilacap. Perhitungan daya dukung pondasi tiang pancang dilakukan dengan memperhitungkan datadata seperti data SPT, Faktor keamanan, dan titik tanah yang ditinjau. Perhitungan daya dukung pondasi tiang dengan metode perhitungan L. Decourt (1982) sebaiknya tidak dianggap sebagai daya dukung pondasi ultimit yang sebenarnya. Untuk memastikan keakuratan hasil analisa struktur dengan metode L. Decourt (1982) diperlukan perbandingan dengan data daya dukung pondasi tiang dengan menggunakan pengujian PDA (Pile Driving Analysis).
\end{abstract}

Kata Kunci : Tiang Pancang, Daya Dukung, Perbandingan, L. Decourt, PDA

\section{PENDAHULUAN}

Kapasitas dukung tanah, adalah kemampuan tanah dalam menahan beban dari struktur - struktur yang berada diatasnya. Beban yang diterima oleh struktur-struktur diatas tanah, akan diteruskan ke dalam tanah oleh pondasi.

Pondasi adalah suatu bagian dari konstruksi bangunan yang berfungsi untuk menempatkan bangunan dan meneruskan beban yang disalurakan dari struktur atas ke tanah dasar yang cukup kuat menahan beban tanpa terjadi kegagalan pada sistem struktur. Salah satu jenis pondasi tiang adalah pondasi tiang pancang.

Daya dukung pondasi tiang pancang dapat ditentukan berdasarkan tahanan ujung (End Bearing) dan pelekatan (Friction) tiang dengan tanah. Kapasitas daya dukung Pondasi tiang dapat diketahui dengan menganalisa data SPT hasil pengujian tanah lapangan yang sudah didapat, atau dengan mengujinya menggunakan tes PDA (Pile Driving Analysis).

Penulisan artikel ini didasari pada rasa keingintahuan penulis tentang seberapa besar perbedaan daya dukung ijin ultimate tiang pancang jika dihitung dengan analisa metode L. Decourt dan pengujian PDA, karena pada dasarnya daya dukung ultimate ijin yang dihitung dengan metode L. Decourt (1982) hanyalah sebuah perkiraan daya dukung ijin ultimate tiang, dan bukan merupakan daya dukung ijin ultimate tiang yang sebenarnya.

\section{TINJAUAN PUSTAKA}

Metode L. Decourt (1982)

- kapasitas daya dukung ultimate tiang

$Q_{u}=Q_{p}+Q_{s}$ 
dengan ,

$Q_{u} \quad$ : kapasitas daya dukung ultimate axial tiang (ton)

$Q_{p} \quad$ : kapasitas daya dukung ujung ultimate tiang (ton)

$Q_{S} \quad:$ Tahanan geser selimut tiang ultimate (ton)
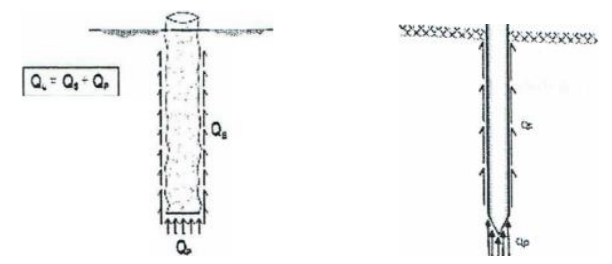

Gambar 1. Gaya Dukung Aksial Pondasi Tiang

- Kapasitas daya dukung ujung tiang :

$Q_{p}=N_{p}{ }^{*} \mathrm{~K}^{*} A_{p}$

dengan,

$N_{p \prime} \quad$ : Nilai rata-rata SPT pada bagian ujung tiang (blow/foot)

K : Koefisien tanah untuk metode L. Decourt (1982) $\left(\right.$ ton $\left./ m^{2}\right)$ (Tabel 1.)

$A_{p} \quad$ : Luas penampang bagian ujung tiang $\left(\mathrm{m}^{2}\right)$

Tabel 1. Koefisien tanah menurut L. Decourt (1982)

\begin{tabular}{|c|c|}
\hline Jenis tanah & Nilai K $\left(\right.$ ton $\left./ m^{2}\right)$ \\
\hline Lempung & 12 \\
\hline Lanau berlempung & 20 \\
\hline Lanau berpasir & 25 \\
\hline Pasir dan Kerikil & 40 \\
\hline
\end{tabular}

- Tahanan geser selimut tiang :

Untuk mencari daya dukung selimut tiang perlu mempertimbangkan rata-rata nilai Nspt sepanjang tiang yang tertanam. Namun nilai $\mathrm{N}$ yang diambil untuk memperkirakan besarnya daya dukung ujung tiang tidak boleh dipakai untuk memperkirakan besarnya daya dukung selimut tiang.

Besarnya daya dukung selimut tiang dapat dinyatakan dengan :

$Q_{s}=q_{s}{ }^{*} A_{s}$

$q_{s}=N_{s} / 3+1$

dengan ,

$N_{S}$ : Nilai rata-rata SPT selimut tiang sepanjang tiang tertanam (blow/foot) 
$N_{S}:\left(N_{S 1}+N_{S 2}+\ldots \ldots+N_{S n}\right) / n$

Para insyinyur belanda sering menggunakan qc pada batas $300 \mathrm{~kg} / \mathrm{cm}^{2}$ dan qc utama maksimum $150 \mathrm{~kg} / \mathrm{cm}^{2}$ untuk tanah berpasir dan $100 \mathrm{~kg} / \mathrm{cm}^{2}$ untuk tanah pasir yang sangat berlumpur. (sumber : cone penetration test,Performance and Design pasal 4.1 hal 24)

- Kapasitas Daya Dukung ljin Tiang

$Q_{\text {all }}=\frac{Q_{u l t}}{S F}$

dengan ,

$Q_{\text {all }} \quad$ kapasitas daya dukung ijin tiang (ton)

SF : Angka keamanan

Berdasarkan AASHTO 1992 menyarankan penggunaan SF sebesar 2,5 untuk kapasitas tiang.

\section{METODE PENELITIAN}

\section{Metode Analisa Data}

Analisa data pada artikel ini dibagi menjadi beberapa bagian seperti, analisa beban rencana yang dihitung dengan bantuan aplikasi SAP 2000 v17, analisa daya dukung tiang pancang yang dihitung dengan metode L. Decourt dengan menggunakan data SPT hasil pengujian tanah di lokasi dermaga IV pelabuhan Tanjung Intan Cilacap dan analisa daya dukung tiang pancang dengan tes PDA.

\section{Lokasi Pengujian}

Pengujian tanah dilakukan di lokasi B2, B3, dan B4 pada tanah laut di sekitar dermaga IV pelabuhan Tanjung Intan kabupaten Cilacap, provinsi Jawa Tengah. Data tanah yang digunakan pada artikel ini adalah tanah B4.

Pengujian PDA (Pile Driving Analysis) dilakukan untuk tiang pancang diameter 812 mm. Pengujian dilakukan pada dua titik pondasi,yaitu pada titik A4 dan E4.

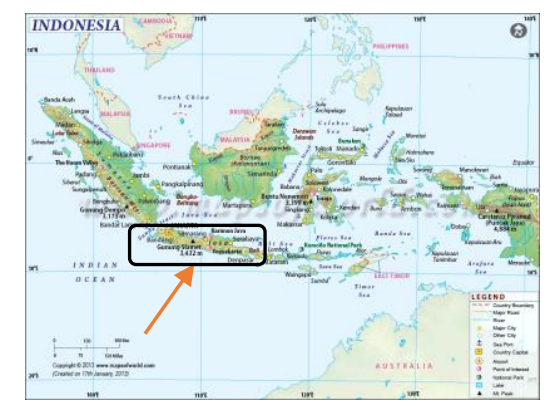

Gambar 2. Lokasi Studi Kajian

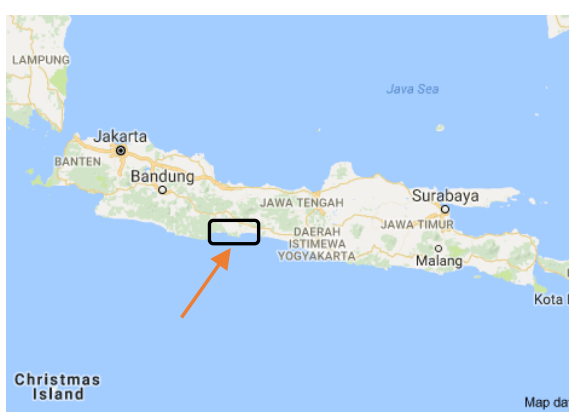

Gambar 3. Lokasi Studi Kajian 


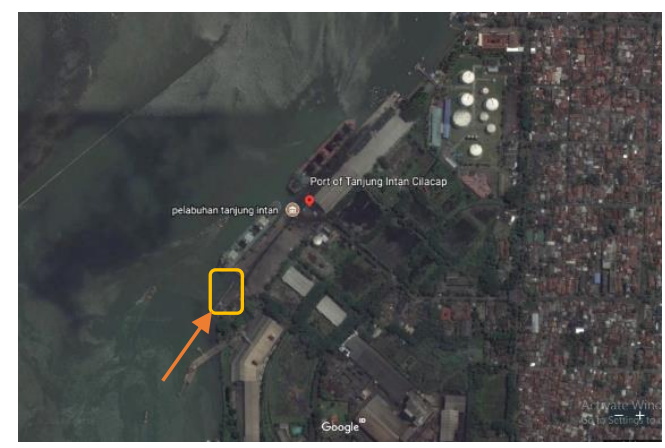

Gambar 4. Lokasi Studi Kajian

\section{Alat Analisa Data}

Data beban rencana struktur dermaga pelabuhan Tanjung Intan Cilacap dianalisa menggunakan bantuan aplikasi struktur SAP 2000v17 dan tes PDA.

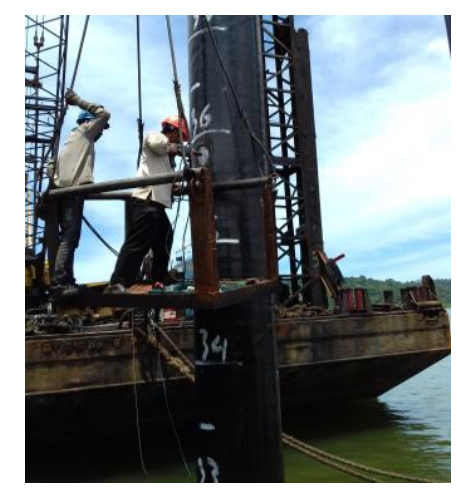

Gambar 5. Persiapan Tes PDA

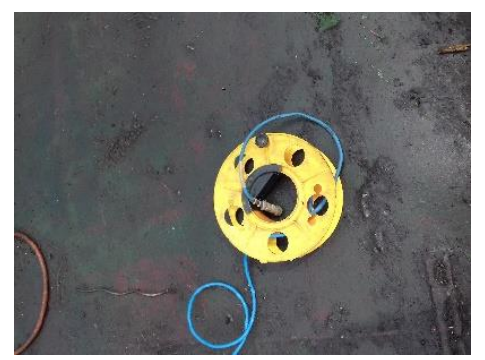

Gambar 6. Alat Untuk Tes PDA

\section{HASIL PEMBAHASAN}

\section{Analisa Beban Rencana}

Beban rencana yang digunakan dalam analisa struktur dermaga IV pelabuhan tanjung intan mengacu pada kriteria desain dan kajian teknis yang telah disetujui. Beban rencana terdiri dari :

a. Beban Mati struktur

Beban mati atau berat sendiri struktur yang diperhitungkan meliputi:

- Beban beton kering $=2,40$ ton $/ \mathrm{m}^{3}$

- Beban beton basah

- Beban beton prestress

$$
=2,50 \text { ton } / \mathrm{m}^{3}
$$

- Beban baja

- Beban pasir

- Beban aspal beton

- Beban kayu

$$
\begin{array}{r}
=2,45 \mathrm{ton} / \mathrm{m}^{3} \\
=7,85 \mathrm{ton} / \mathrm{m}^{3}
\end{array}
$$

$$
=1,80 \text { ton } / \mathrm{m}^{3}
$$$$
=2,30 \text { ton } / \mathrm{m}^{3}
$$

Serta beban mati tambahan yang meliputi :

- Beban Bollard

= 3 ton (asumsi) 
- Beban Fender

b. Beban Hidup

- Beban hidup merata

Beban truck dengan be

- Beban Harbour portal crane (HPC) saat beroperasi

- Beban Container Crane (CC) saat beroperasi

- Beban Harbour Mobile Crane (HMC) dengan beban merata sebesar 2,41 ton $/ \mathrm{m}^{2}$

c. Beban Kapal

Beban kapal merupakan beban langsung yang diakibatkan oleh sandar dan tambat kapal. Beban ini ditransformasikan pada struktur melalui fender, dan bollard. Hal yang diperhitungkan adalah kecepatan sandar kapal seta reaksi fender dan bollard.

d. Beban Lingkungan

- Beban Arus

Kecepatan normal

Kecepatan Extreme

- Beban Angin

Kecepatan normal

Kecepatan Extreme

- Beban Gelombang

Tinggi gelombang

- Beban Temperature

Perbedaan temperature yang terjadi diasumsikan sebesar $15^{\circ} \mathrm{C}$

e. Beban Gempa

Beban gempa diperhitungkan berdasarkan SNI-1726-2012 untuk tanah sedang.

f. Kombinasi pembebanan

Seluruh kombinasi pembebanan akan diperhitungkan dalam perencanaan struktur jetty. Kombinasi pembebanan dilakukan berdasarkan POLB (Port of Long Beach) dengan kondisi service dan ultimate.

Tabel 2. Faktor Beban dan Kombinasi Pembebanan

\begin{tabular}{|c|c|c|c|c|c|c|c|c|c|c|}
\hline \multicolumn{11}{|c|}{ Load Factor Design } \\
\hline \multirow{2}{*}{ Case } & \multicolumn{10}{|c|}{ Load Combination Factors } \\
\hline & $\mathrm{D}$ & $L+1$ & $\mathrm{E}$ & & & $\mathrm{BE} \quad \mathrm{R}$ & $\mathrm{R}+\mathrm{S}+\mathrm{T}$ & $\mathrm{EQ}$ & $\mathrm{BU}$ & M \\
\hline $\mathbf{I}$ & 1,2 & 1.6 & 1,6 & & & - & - & - & 1,3 & - \\
\hline II & 1,2 & 1.0 & 1.6 & 1.6 & & - & 1.2 & - & 1,3 & - \\
\hline III & 0.9 & - & 1,6 & 1.6 & & - & 1.3 & - & 1,3 & - \\
\hline$! \Lambda^{\prime}$ & 1,2 & 0,1 & 1,6 & 1.0 & & 1.6 & - & - & 1,3 & - \\
\hline$\backslash^{\prime}$ & 1,2 & 1,0 & 1,6 & 1,3 & & - & - & - & 1,3 & 1,3 \\
\hline \multirow[t]{2}{*}{ \I } & 1,2 & 0,1 & 1,0 & & & - & - & 1.0 & - & - \\
\hline & \multicolumn{10}{|c|}{ Service Load Design } \\
\hline \multirow{2}{*}{ Case } & \multicolumn{9}{|c|}{ Load Combination Factor } & \multirow[b]{2}{*}{$\begin{array}{c}\text {-I.llowabe } \\
\text { Stress }\end{array}$} \\
\hline & D & $\mathrm{L}+\mathrm{I}$ & $\mathrm{E}$ & 11 & $\mathrm{BE}$ & $R+S+T$ & $\mathrm{EQ}$ & $\mathrm{BU}$ & $\mathrm{y}[$ & \\
\hline 1 & 1.0 & 1,0 & 1,0 & - & - & - & - & 1.0 & - & $100 \%$ \\
\hline II & 1,0 & 1,0 & 1,0 & 1,0 & - & 1.0 & - & 1,0 & - & $133 \%$ \\
\hline III & 1.0 & - & 1,0 & 1,0 & - & 1.0 & - & 1.0 & - & $125 \%$ \\
\hline IV & 1,0 & 0.1 & 1,0 & 0,3 & 1.0 & - & - & 1.0 & - & $100 \%$ \\
\hline V & 1,0 & 1,0 & 1.0 & 1,0 & - & - & - & 1,0 & 1.0 & $125 \%$ \\
\hline
\end{tabular}

dengan ,

$\mathrm{DL}:$ dead load ( ton $/ \mathrm{m}^{3}$ )

$\mathrm{L} \quad$ : live load ( ton $/ \mathrm{m}^{2}$ )

$\mathrm{W}$ : wind load (KN)

$\mathrm{BE}$ : berthing Energy (ton $/ \mathrm{m})$

\section{- Reaksi Perletakan}

Reaksi perletakan adalah reaksi yang secara umum mepelajari tentang ilmu kesetimbangan gaya gaya yang bekerja pada suatu konstruksi. 
Reaksi perletakan disini dihitung sebagai beban rencana terpusat pada satu titik tiang pancang.

Tabel 3. Hasil Perhitungan reaksi Perletakan Operasional

\begin{tabular}{|c|c|c|c|c|c|c|c|c|}
\hline \multicolumn{9}{|c|}{ TABLE : Joint Reactions } \\
\hline Axis & Pile Type & Case Type & F1 & F2 & F3 & M1 & M2 & M3 \\
\hline Text & \begin{tabular}{|l|} 
Text \\
\end{tabular} & Text & Ton & Ton & Ton & Ton-m & Ton-m & Ton-m \\
\hline \multirow{2}{*}{ A } & SPP $\varnothing 812$, & Min & -1.020 & -2.701 & 54.470 & -11.740 & -10.940 & -1.165 \\
\hline & $\mathrm{t}=16 \mathrm{~mm}$ & Max & 1.465 & 0.863 & 250.830 & 28.749 & 14.661 & 1.006 \\
\hline \multirow{2}{*}{ B } & SPP $\varnothing 711.2$ & Min & -0.828 & -2.607 & 25.821 & \begin{tabular}{|l|}
-13.638 \\
\end{tabular} & -7.901 & -0.841 \\
\hline & $\mathrm{t}=16 \mathrm{~mm}$ & Max & 1.216 & 1.383 & 120.942 & 24.495 & 11.109 & 0.737 \\
\hline \multirow{2}{*}{ C } & SPP $\varnothing 711.2$ & Min & -12.175 & -20.004 & -90.267 & -16.780 & -7.388 & -4.599 \\
\hline & $\mathrm{t}=16 \mathrm{~mm}$ & Max & 16.714 & 14.945 & 141.017 & 26.313 & 11.966 & 3.747 \\
\hline \multirow{2}{*}{$D$} & SPP $\varnothing 711.2$ & Min & -0.836 & -3.450 & 34.196 & -18.644 & -7.015 & -0.966 \\
\hline & $\mathrm{t}=16 \mathrm{~mm}$ & Max & 1.694 & 2.283 & 165.649 & 29.482 & 13.605 & 0.820 \\
\hline \multirow{2}{*}{$E$} & SPP $\varnothing 812$, & Min & -1.765 & -6.248 & 41.627 & -29.710 & -13.848 & -1.539 \\
\hline & $\mathrm{t}=16 \mathrm{~mm}$ & Max & 2.986 & 3.955 & 238.981 & 50.083 & 22.472 & 1.320 \\
\hline \multirow{2}{*}{$\mathrm{F}$} & SPP $\varnothing 711.2$, & Min & -1.529 & -5.096 & 25.048 & -23.377 & -11.732 & -1.079 \\
\hline & $\mathrm{t}=16 \mathrm{~mm}$ & Max & 1.964 & 3.277 & 132.635 & 38.172 & 14.608 & 0.899 \\
\hline \multirow{2}{*}{ G } & SPP $\varnothing 711.2$ & Min & -2.116 & -6.174 & 23.762 & -26.413 & -15.260 & -1.229 \\
\hline & $\mathrm{t}=16 \mathrm{~mm}$ & Max & 2.505 & 3.765 & 83.937 & 43.337 & 16.960 & 0.959 \\
\hline \multirow{2}{*}{$\mathrm{H}$} & SPP $\varnothing 711.2$ & Min & -4.955 & -7.641 & 12.212 & -30.872 & -21.447 & -1.386 \\
\hline & $\mathrm{t}=16 \mathrm{~mm}$ & Max & 2.573 & 4.766 & 104.483 & 49.898 & 17.067 & 1.035 \\
\hline
\end{tabular}

Didapat reaksi perletakan maksimum F3 :

Untuk tiang pancang D80 $\mathrm{cm} \quad=250,830$ ton

\section{Analisa Daya Dukung Tiang Pancang dengan Metode L. Decourt (1982)}

Desain tiang pancang pipa baja berdasarkan AISC - ASD 89

- Menghitung kapasitas daya dukung ultimate tiang

$Q_{u}=Q_{p}+Q_{s}$

- Menghitung kapasitas daya dukung ujung tiang :

$Q_{p}=N_{p}{ }^{*} \mathrm{~K}^{*} A_{p}$

- Menghitung tahanan geser selimut tiang :

$Q_{s}=q_{s}{ }^{*} A_{S}$

$q_{s}=N_{s} / 3+1$

- Menghitung Kapasitas Daya Dukung ljin Tiang

$Q_{\text {all }}=\frac{Q_{u l t}}{S F}$

- Hasil Perhitungan Kapasitas Daya Dukung Tiang :

Kapasitas daya dukung tiang pancang diameter $812 \mathrm{~mm}$ berdasarkan data tanah lokasi B4 adalah sebagai berikut : 
Tabel 4. Daya dukung TP D812 mm berdasar data tanah B4

\begin{tabular}{|l|l|l|l|l|l|l|l|l|l|l|l|l|l|}
\hline Depth & $\begin{array}{l}\text { Elev } \\
(\mathrm{mLWS})\end{array}$ & $\mathrm{N}$ & $\mathrm{N}^{\prime}$ & $N_{p \prime}$ & $\mathrm{K}$ & $A_{p}$ & $Q_{p}$ & $N_{s 1}$ & $N_{s}$ & $q_{s}$ & $A_{s}$ & $Q_{s}$ & $\begin{array}{l}Q_{L} \\
\text { (ton) }\end{array}$ \\
\hline 10,25 & $-22,25$ & 0 & 7,5 & 7,8 & 25 & 0,51785 & 100,9 & 3 & 3 & 2 & 26,11 & 52,3 & 153,7 \\
\hline 12,50 & $-24,50$ & 17 & 16 & 14,2 & 25 & 0,51785 & 183,8 & 17 & 10 & 4,3 & 31,89 & 138,2 & 321,6 \\
\hline 16,50 & $-28,50$ & 23 & 19 & 15 & 25 & 0,51785 & 194,2 & 23 & 14,3 & 5,8 & 42,09 & 243,2 & 437,4 \\
\hline 20,00 & $-32,00$ & 5 & 10 & 15,3 & 20 & 0,51785 & 158,5 & 5 & 12 & 5 & 51,02 & 255,1 & 413,9 \\
\hline 22,50 & $-34,50$ & 19 & 17 & 17,7 & 20 & 0,51785 & 183,3 & 19 & 13,4 & 5,5 & 57,4 & 313,8 & 496,7 \\
\hline 25,00 & $-37,50$ & 37 & 26 & 24,3 & 20 & 0,51785 & 251,7 & 37 & 17,3 & 6,8 & 63,77 & 432,3 & 684,3 \\
\hline 27,50 & $-39,50$ & 45 & 30 & 27,8 & 20 & 0,51785 & 287,9 & 45 & 21,3 & 8,1 & 70,15 & 567,9 & 856,2 \\
\hline 32,50 & $-42,50$ & 40 & 27,5 & 30,7 & 20 & 0,51785 & 318,0 & 40 & 23,6 & 8,9 & 82,91 & 735,8 & 1053,4 \\
\hline 35,00 & $-47,00$ & 54 & 34,5 & 29,7 & 20 & 0,51785 & 307,6 & 50 & 26,6 & 9,9 & 89,28 & 879,6 & 1186,9 \\
\hline 37,50 & $-49,50$ & 39 & 27 & 33 & 20 & 0,51785 & 341,8 & 39 & 27,8 & 10,3 & 95,66 & 982,1 & 1323,9 \\
\hline 40,00 & $-52,00$ & 60 & 37,5 & 33,7 & 20 & 0,51785 & 349,0 & 50 & 29,8 & 10,9 & 102,04 & 1116,2 & 1813,6 \\
\hline 42,50 & $-54,50$ & 58 & 36,5 & 35,8 & 40 & 0,51785 & 741,6 & 50 & 31,5 & 11,5 & 108,42 & 1246,8 & 1989 \\
\hline
\end{tabular}

Didapatkan $Q_{L}$ untuk kedalaman -29,250 m dari permukaan air laut adalah sebesar 856,2 ton.

Keterangan :

Depth : panjang tiang tertanam $(\mathrm{m})$

Elev $\quad$ : elevasi ujung tiang pondasi dari muka air laut (mLWS)

N : Nilai rata-rata Standard Penetration Test (SPT) (blow/foot)

$N_{S 1} \quad$ : Nilai rata-rata SPT selimut tiang

Nilai rata rata SPT didapat dari hasil pengujian Standard Penetration Test di tanah dermaga IV pelabuhan Tanjung Intan Cilacap. Standard tentang"cara uji penetrasi lapangan dengan SPT"di indonesia adalah SNI 4153-2008 , (yang merupakan revisi dari SNI 03-41531996) yang mengacu pada ASTM D 1586-84 "Standard penetration test and split barrel sampling of soils".

Uji SPT terdiri atas uji pemukulan tabung belah dinding tebal ke dalam tanah, disertai pengukuran jumlah pukulan untuk memasukkan tabung belah sedalam $300 \mathrm{~mm}$ vertikal. Dalam sistem beban jatuh ini digunakan palu dengan berat $63,5 \mathrm{Kg}$, yang dijatuhkan secara berulang dengan tinggi jatuh $0,76 \mathrm{~m}$. Pelaksanaan pengujian dibagi dalam tiga tahap, yaitu berturut-turut setebal $150 \mathrm{~mm}$ untuk masing-masing tahap. tahap pertama dicatat seebagai dudukan, sementara jumlah pukulan untuk memesukkan tahap kedua dan ketiga dijumlahkan untuk memperoleh nilai pukulan $\mathrm{N}$ atau perlawanan SPT (dinyatakan dalam pukulan/0,3 m).

Panjang tiang rencana yaitu 45m untuk D812 mm.

Panjang tiang tertanam untuk pipa sepanjang $45 \mathrm{~m}$ adalah sebagai berikut :

- Elevasi dek

- Cut off level

- Elevasi seabed

- Panjang tiang tertanam
$=+3.88 \mathrm{~m}$ (referensi 0,00 LWS)

= rata-rata $+3.00 \mathrm{~m}$

$=-12 \mathrm{~m}$ (dari LWS)

$=45-(3+12)=30 \mathrm{~m}$ 
Tabel 5. Perhitungan Kapasitas Tiang Pancang

\begin{tabular}{|l|l|l|l|l|l|}
\hline NO & Diameter tiang & $L$ total $(\mathrm{m})$ & $\mathrm{L}$ tertanam $(\mathrm{m})$ & $\begin{array}{l}\text { Beban rencana } \\
\text { ultimate (ton) } \\
\mathrm{F} 3 \mathrm{max}{ }^{*} \mathrm{SF}\end{array}$ & $\begin{array}{l}\text { Daya Dukung } \\
\text { tanah }\left(Q_{L}\right) \text { (ton) }\end{array}$ \\
\hline 1 & SPP $812 \mathrm{~mm}$ & 45 & 30 & $250,83^{*} 2,5=627,07$ & 856,20 \\
\hline
\end{tabular}

Berdasarkan perhitungan pada Tabel 5.,daya dukung tanah pada kedalaman rencana lebih besar dari beban rencana, maka struktur tersebut aman dari kegagalan struktur.

\section{Hasil Perhitungan Daya Dukung Tiang dengan Tes PDA (Pile Driving Analysis)}

Untuk memperkirakan daya dukung tiang, dilakukan pengetesan dengan menggunakan metode pile driving analysis. Tes PDA dilakukan di tiang yang sudah dipancang, kemudian Dynamic Loading Test dilakukan dengan memasang strain transducers dan accelerometer pada bagian atas tiang yang ditest, lalu tiang akan dipukul kembali untuk mengetahui daya dukung tiang (RU) dan hasilnya dianalisa dengan Pile Dynamic Analyzer (PDA). Tes ini dilakukan dengan mengikuti standard ASTM D- 4845-89.

Tabel 6. Hasil pengujian PDA tiang D812 mm

\begin{tabular}{|c|c|c|}
\hline \multicolumn{3}{|l|}{ DATA FONDASI - TIANG \& HAMMER } \\
\hline No. Tiang & A4 & E4 \\
\hline Tanggal pemancangan & $12 / 02 / 2017$ & $18 / 01 / 2017$ \\
\hline Tanggal pengujian & $19 / 02 / 17$ & $19 / 02 / 17$ \\
\hline Jenis tiang & Baja & Baja \\
\hline Diameter luar;tebal (mm) & $812 ; 16$ & $812 ; 16$ \\
\hline Panjang total saat uji (m) & 45 & 45 \\
\hline Panjang senor (m ) & 40 & 37 \\
\hline Panjang tertanam $(\mathrm{m})$ & 24 & 25 \\
\hline Panjang impact & DD83 & DD83 \\
\hline Berat sumber impact (ton) & 8,3 & 8,3 \\
\hline \multicolumn{3}{|c|}{ PENGUKURAN/MEASUREMENTS (berdasarkan case method) } \\
\hline RMX/RA2/RSU (Pile capacity)[tons] & $678 / 697$ & $684 / 742$ \\
\hline FMX(max compession force)[tons] & 490 & 513 \\
\hline EMX (maximun tranferred energy)[tons.m] & 10,15 & 10,7 \\
\hline CSX(max compession stress)[Mpa] & 120 & 125,7 \\
\hline TSX(max tension rate)[Mpa] & 75,6 & 82,1 \\
\hline DMX(max displacement)[mm] & 29 & 29 \\
\hline DFN(final displacement)[mm] & 0 & 0 \\
\hline BTA(pile integrity value)[\%] & 100 & 100 \\
\hline \multicolumn{3}{|l|}{ HASIL (berdasarkan analisis CAPWAP) } \\
\hline Daya dukung fondasi tiang $\left(R_{U}\right)[$ ton] & 630 & 640 \\
\hline Lengketan $\left(R_{s}\right)[$ ton] & 480 & 463 \\
\hline
\end{tabular}




\begin{tabular}{|l|l|l|} 
Tahanan Ujung $\left(R_{b}\right)[$ ton $]$ & 150 & 177 \\
\hline Daya dukung tarik $\left(R_{U P}\right)\left(80 \%^{*} R_{S}\right)[$ ton $]$ & 384 & 370,4 \\
\hline Keutuhan fondasi tiang & OK & OK \\
\hline
\end{tabular}

Dari hasil pengujian kuat tekan pondasi tiang pancang $\mathrm{D} 812 \mathrm{~mm}$ dengan pengujian PDA pada titik A4 dan E4, dengan panjang tiang tertanam $=24 \mathrm{~m}$ dan $25 \mathrm{~m}$, didapat daya dukung pondasi tiang $(R U)=630$ ton dan 640 ton. Dengan beban rencana sebesar 627,07 ton, maka struktur tersebut aman dari kegagalan struktur.

\section{Perbandingan Daya Dukung Pondasi dengan Metode L. Decourt dan Tes PDA}

-Titik A4

Berdasarkan hasil tes PDA pada titik A4, diketahui bahwa:

-Panjang tiang tertanam $\quad=24 \mathrm{~m}$

-Daya dukung fondasi $\left(R_{U}\right) \quad=$ Lengketan $\left(R_{S}\right)+$ Tahanan ujung $\left(R_{b}\right)$

Bisa dijadikan rumus, $Q_{U} \quad=Q_{s}+Q_{p}$

$$
\begin{aligned}
& =480+150 \\
& =630 \text { ton }
\end{aligned}
$$

Berdasarkan analisa Struktur dengan data tanah pada pengeboran lokasi B4, dengan mengambil data tiang tertanam sepanjang $25 \mathrm{~m}$, didapat :

$$
\begin{aligned}
Q_{L} \quad & =Q_{p}+Q_{s} \\
& =252+432,3 \\
& =684,3 \text { ton } \\
Q_{L} & =Q_{U}
\end{aligned}
$$

Dari kedua data diatas, diketahui bahwa perbedaan daya dukung fondasi berdasarkan tes PDA dan analisa struktur adalah sebesar 54,3 ton.

Dengan beban rencana sebesar 627,07 ton, maka struktur tersebut aman dari kegagalan struktur.

- Titik E4

Berdasarkan hasil tes PDA pada titik E4, diketahui bahwa:

- Panjang tiang tertanam $=25 \mathrm{~m}$

- Daya dukung fondasi $\left(R_{U}\right)=$ Lengketan $\left(R_{S}\right)+$ Tahanan ujung $\left(R_{b}\right)$

Bisa dijadikan rumus, $Q_{U} \quad=Q_{s}+Q_{p}$

$$
\begin{aligned}
& =463+177 \\
& =640 \text { ton }
\end{aligned}
$$

Berdasarkan analisa Struktur dengan data tanah pada pengeboran lokasi B4, dengan mengambil data tiang tertanam sepanjang $25 \mathrm{~m}$, didapat :

$$
\begin{aligned}
Q_{L} & =Q_{P}+Q_{S} \\
& =252+432,3 \\
& =684,3 \text { ton } \\
Q_{L} & =Q_{U}
\end{aligned}
$$


Dari kedua data diatas, diketahui bahwa perbedaan daya dukung fondasi berdasarkan tes PDA dan analisa struktur adalah sebesar 44,3 ton.

Dengan beban rencana sebesar 627,07 ton, maka struktur tersebut aman dari kegagalan struktur.

\section{KESIMPULAN}

Berdasarkan hasil analisis maka diperoleh kesimpulan sebagai berikut :

1.Berdasarkan perhitungan daya dukung pondasi dengan metode L. Decourt (1982) maupun pengujian dengan PDA (Pile Driving Analisys) dapat diketahui bahwa daya dukung pondasi tiang diameter $812 \mathrm{~mm}$ dengan data tanah B4 untuk kedalaman tiang tertanam sepanjang > $24 \mathrm{~m}$ sudah melebihi beban rencana. Oleh karena itu dapat disimpulkan bahwa tiang pancang tersebut mampu untuk memikul beban melebihi beban rencana.

2.Berdasarkan perbandingan perhitungan daya dukung pondasi dengan metode L. Decourt (1982) dan pengujian dengan metode PDA didapatkan perbedaan kapasitas daya dukung ultimate pondasi $<60$ Ton.

\section{DAFTAR PUSTAKA}

Surahman , Maman . 2016.Analisis Daya Dukung Tiang Pancang Menggunakan Data Insitu Test,Parameter Laboratorium Terhadap Loading Test Kantledge,Hal 65-68.Jakarta:Teknik Sipil UMJ

Kusumawardani , R. , Apriyatno , H. , Rachmawati , R. J. , Anggraini , R. ,2016.Analisis Daya Dukung Pondasi Tiang-Rakit Pada Daerah Rawan Gempa Menggunakan Metode Poulus Dan Program Numeris Plaxis,Hal 127-138.Semarang:Teknik Sipil UNNES

Pangestuti , E. K. , Kusumawardani , R. , Priaji , A. , Nikmah , D. L. ,2016.Perbandingan Analisa Perhitungan Beton Struktural Pada Proyek Pembangunan Gedung F Universitas Pekalongan,Hal 159-164.Semarang:Teknik Sipil UNNES

Fatimah , Ayu Zahra . , 2013.Daya Dukung Pondasi Dengan Analisis Terzaghi. www.slideshare.net

Azwaruddin . , 2008.Pengetian Pondasi.http://azwaruddin.blogspot.co.id/2008/06/pengertianpondasi.html?m=1

Admin ., 2016.Rumus Mencari SPT Pada Borring Test.http://www.ngekul.com/rumus-mencari-sptpada-borring-test/ 